\title{
Well-trained staff is the key to the success of urodynamic testing
}

\author{
Richard J. Baverstock, MD \\ vesia [Alberta Bladder Centre], University of Calgary, Calgary, AB, Canada
}

Cite as: Can Urol Assoc J 2016;10(5-6):191. http://dx.doi.org/10.5489/cuaj.3822

See related article on page 187.

I enjoyed reading this paper from the Methodist Hospital in Houston because it is practical and had a simple purpose: to see if they could find a way to make urodynamic studies (UDS) more comfortable. ${ }^{1}$ They believed that allowing patients to wear headphones and select their music would result in lower pain and anxiety scores. The authors conclude that personal selection of music during UDS testing did not improve pain scores. Remarkably, both groups of patients, with music and without music, found UDS to be extremely well-tolerated with visual analogue scores (VAS) of 1.04 and 1.57, respectively. I've often thought I would pass out at the insertion of a xylocaine jelly in cystoscopy, so I marvelled at the fact that these patients are clearly tough. As the authors point out, this is actually the second negative study to show that catheterizing to Coldplay or voiding with Vivaldi isn't required for a comfortable UDS experience.

Unlike the Solomon group, which enrolled female patients only, ${ }^{2}$ this study included a cohort of men and neurogenic patients. Perhaps an explanation as to why the pain and mean satisfaction score for UDS was so low lies in the fact that UDS is not typically the first time something goes up the male or neurogenic urethra in urological practice. Many men have experienced a 16 French flexible cystoscopy and most neurogenic bladder patients might have experienced a catheterization prior to a UDS being performed. I wonder if the pain scores for patients whose first instrumentation is with UDS would show that they don't tolerate this as well. The authors questioned whether a difference would be found if more patients were enrolled, but honestly, the scores were so low that it would be hard to imagine a better experience is possible.

Prior to reading this manuscript, I was not familiar with the State Trait Anxiety Inventory (STAI). It appears to be a commonly used measure for anxiety. I got anxious just reading the questionnaire and although I'm a huge advocate for patient-reported outcomes (PROs), the STAI, with options like: "I feel pleasant," "I feel indecisive," "I wish I could be as happy as others seem to be," doesn't feel like the best PRO for the experience of UDS. However, it is a well-used and well-respected inventory and I congratulate the authors

for kicking it up a notch and employing a PRO like this.

The most valuable lesson learned is one that we have recently battled with in Calgary. UDS must be performed by well-trained and knowledgeable staff. It is not a simple test and involves skilled personnel who must be experts in the history-taking, catheterization, zeroing, and calibration right through to the software nuances and adjustments made while testing. For physicians to get the answer to the question they wanted from a UDS, the staff is critical and this can only be learned with experience in urology, mentoring from experts, and involvement of the urodynamicist.

Moving a UDS program because of budgetary or staffing needs without consideration of the expertise required to run this test is fraught with harm to patients. The Methodist group confirmed this by stating, "The most important aspect of alleviating pain and anxiety was the person actually performing the urodynamics testing." ${ }^{11}$ As a urologist interpreting UDS and performing video UDS, I would echo that statement and add to it that having the best-trained staff reduces my pain and anxiety. The result is a test that answers the important questions - "Does this man need a third TURP?" or "Will this bladder destroy the kidneys?"

So the message is "loud and clear" from this study by Khavari et al. Before you pimp your UDS suite out with Bose speakers, ensure that the staff performing the test are well-trained, compassionate healthcare professionals. The patient will be most relaxed, cooperative, and tolerant when a professional is "in the house."

Competing interests: Dr. Baverstock has been an Advisory Board member for Allergan, Astellas, and Pfizer; a member of a Speakers' Bureau for Allergan, AMS, Astellas, and Pfizer; received payment/grants/honoraria from Allergan, AMS, Astellas, and Pfizer; and participated in clinical trials for Allergan, Astellas, and Pfizer.

\section{References}

1. Khavari R, Gu C, Tran AC, et al. Trained and dedicated staff appears to be the main factor in decreasing anxiety and improving overall satisfaction during urodynamic testing: A prospective, randomized trial. Can Urol Assoc J 2016;10:187-90. http://dx.doi.org/10.5489/cuaj.3421

2. Solomon ER, Ridgeway $B$. Interventions to decrease pain and anxiety in patients undergoing urodynamic testing: A randomized, controlled trial. Neurourol Urodyn 2015; July 30. [Epub ahead of print]. http:// dx.doi.org/10.1002/nau.22840

Correspondence: Dr. Richard Baverstock, vesia [Alberta Bladder Centre], University of Calgary, Calgary, AB, Canada; richard.baverstock@ahs.ca 